\title{
Literatura comunista mundial
}

\author{
Jorge Amado en la República Democrática Alemana y China
}

I

La historia de la literatura latinoamericana más difundida y reproducida hace pie en el relato articulado por Carlos Fuentes, Mario Vargas Llosa y José Donoso en sus conocidos textos dedicados a retratar a la generación de la que ellos fueron parte ${ }^{1}$. De acuerdo con algunos de los argumentos expuestos en estos ensayos, la novela latinoamericana anterior no habría recibido reconocimiento internacional debido a su "retraso" en relación con los desarrollos apreciables en otras tradiciones literarias. Los años de referencia suelen ser 1961, cuando Jorge Luis Borges recibe, compartido con Samuel Beckett, el Prix International, o 1962, cuando Mario Vargas Llosa se beneficia con el Biblioteca Breve de la editorial Seix Barral por La ciudad y los perros (1963). La internacionalización de la literatura latinoamericana, según la terminología de Donoso, debe ser entendida, entonces, como una actitud deliberada por parte de los escritores de

1 Me refiero, fundamentalmente, a La nueva novela hispanoamericana, de Fuentes (1969), a "Novela primitiva y novela de creación en América Latina” (1969), de Vargas Llosa, y a Historia personal del "boom" (1972), de Donoso. De acuerdo con los planteos desarrollados en tales ensayos, la novela latinoamericana de los años 60 habría reaccionado con éxito al costumbrismo dominante hasta el momento. Al respecto de tal operación crítica, Eduardo Becerra, por su parte, anota que "la importancia de las estrategias mercadotécnicas en la consecución de la fama y el prestigio de la 'nueva novela' de los sesenta facilitó que estas visiones esquemáticas, diría que incluso maniqueas, fuesen dictadas por los propios protagonistas, pues en medio de ese éxito encontraron con gran facilidad lugares desde los que exponer las características y ensalzar los valores del acontecimiento. La nueva novela hispanoamericana, de Carlos Fuentes (1969), y el artículo de ese mismo año escrito por Mario Vargas Llosa: "Novela primitiva y novela de creación en América Latina” (Revista de la Universidad de México, 10, pp. 29-36), constituyen los ejemplos paradigmáticos y archicitados de esta actitud. Ambos trabajos, con títulos que permiten no extenderme mucho sobre el tema dada la nítida intencionalidad a la que apuntan, confrontan el presente de la novela de Hispanoamérica con un pasado en el que el género aparece a sus ojos carente de altura estética, meramente documental o ligado exclusivamente a lo geográfico, y las excepciones que se citan son remitidas y limitadas a su condición de antecedentes de un rumbo nuevo" (2008: 17). Este último procedimiento, aunque algo más matizado, se registra también en "La nueva novela latinoamericana” (1970), de Emir Rodríguez Monegal.

Jorge J. Locane, Universitetet i Oslo

๑ Open Access. (c) 2021 Jorge J. Locane, published by De Gruyter. (cc) BY-NC-ND This work is licensed under a Creative Commons Attribution-NonCommercial-NoDerivatives 4.0 International License.

https://doi.org/10.1515/9783110713015-013 
su generación para romper con los horizontes de provincias y ajustar las formas a estándares internacionales. Primero la literatura se internacionaliza -en este sentido que propone Donoso- $-y$, recién después, recibe aceptación por parte de los públicos metropolitanos. Primero abjura del costumbrismo, del color local, del realismo, tal vez podríamos decir de la variante más acartonada de la novela de la tierra, y, recién entonces, el público internacional comienza a prestarle atención.

Frente a despliegues retóricos de este tipo, que a la luz de la teoría bourdieana no serían sino un método para ganar terreno en el campo literario, el escepticismo suele ser un buen comienzo; se trata ante todo de desconfiar de los relatos narrados en primera persona. Más aún cuando vienen teñidos de heroicidad o de autoexaltación. El poder performativo de esta intervención crítica es, sin embargo, tan sorprendente como indoblegable. El fenómeno popularizado como boom, al menos para cierta parte de la investigación internacional, suele ser el punto de partida, el big bang, el origen de todo. Una instancia por lo menos ineludible. Frente a este escenario, me gustaría sugerir -como también lo hace Eduardo Becerra en el trabajo ya mencionado- que es necesario rever la historia de la literatura latinoamericana según fue diseñada por los mismos protagonistas del boom y que, básicamente, afirma que antes de su generación no había mucho que mereciera ser traducido e, incluso, que, efectivamente, lo haya habido. Los cuatro o cinco escritores que conforman el círculo de elegidos son, dentro de este esquema, la literatura latinoamericana, con ellos -y dado el caso con algunos de sus allegados-, la literatura latinoamericana comienza. Con ellos, habría que deducir, se acaba.

Desde mi punto de vista, los problemas con este reductivismo maniqueo son muchos; uno no menor es que, en realidad, la enunciación posee un anclaje claramente metropolitano desde el momento que es indiferente a lo que haya pasado o esté pasando en las dependencias (neo)coloniales y en las periferias; lo único que importa -y desde donde se mide el valor del texto- es la llegada, la recepción y la lectura en la metrópoli. Pero, incluso así, incluso tomando como lugar de referencia los centros mundiales de gestión cultural, creo que existen evidencias suficientes para rebatir la entonación épica del boom. Para no abundar, un dato que se podría considerar es que en los quince años que van desde el fin de la Segunda Guerra a 1960 - antes de la operación Formentor, antes del Biblioteca Breve otorgado a Vargas Llosa, antes del boom-, que es cuando los exiliados, como Erich Arendt, Ludwig Renn, Albert Theile 
(véase Locane 2019) y Anna Seghers, vuelven de América ${ }^{2}$, en Alemania aparecen, además de varias antologías, publicaciones individuales de Juan Rulfo (1958), Alejo Carpentier (1958), Jorge Luis Borges (1959), Miguel Ángel Asturias (1956), Pablo Neruda (1949), Alfredo Varela (1952), Nicolás Guillén (1952), Jacques Roumain (1947), Gabriela Mistral (1958), José Eustasio Rivera (1946), Rómulo Gallegos (1952), Ciro Alegría (1945), Enrique Larreta (1958), Jorge Icaza (1952), Elías Castelnuovo (1949), Jorge Amado (1946, 1954, 1958), Volodia Teitelboim (1955), Ventura García Calderón (1956) y varios otros. Que estos escritores, en efecto, hayan sido leídos o no es un elemento que no afecta el planteo, ya que tampoco se puede probar de manera fehaciente que las numerosas traducciones y ediciones de Cien años de soledad (1967), por ejemplo, hayan encontrado lectores.

En términos más generales, se podría sostener que, así como la escena internacional de los años 60 tiene a sus cuatro o cinco protagonistas, la de la inmediata Posguerra también los tiene: son Pablo Neruda, Miguel Ángel Asturias, Nicolás Guillén, Alejo Carpentier y Jorge Amado. En este último voy a centrar los argumentos a continuación. Pero, además de correr el foco hacia un período anterior y hacia otro grupo de escritores que, del mismo modo que los del boom, también conformaron una especie de cofradía, quiero proponer un corrimiento geopolítico hacia el hoy desvanecido y olvidado mundo comunista. La hipótesis de fondo sería que cada "mundo" $u$ orden político-cultural tiende a diseñar una "literatura mundial" a su medida, a su imagen y semejanza. Cada uno de esos mundos, idealmente, dispone de técnicos, editores, traductores, académicos, agentes, gatekeepers ${ }^{3}$, encargados de seleccionar y jerarquizar el corpus que va a entrar en circulación dentro del territorio delimitado como su

2 En su estudio sobre la literatura latinoamericana en la República Democrática Alemana, Jens Kirsten, por ejemplo, anota: "Die wesentlichen neuen Impulse für das Interesse an Lateinamerika mit seiner Kultur und Literatur, die das Lateinamerika-Bild der folgenden Jahre entscheidend prägten, gingen jedoch von den nach Deutschland zurückkehrenden deutschen Exilschriftstellern aus, die vorwiegend aus dem mexikanischen Exil in den Osten Deutschlands zurückkehrten” (2004: 19) [Los nuevos impulsos esenciales para el interés en América Latina con su cultura y literatura, que configuraron de manera decisiva la imagen de América Latina en los años siguientes, provinieron de los escritores alemanes que retornaron a Alemania desde el exilio, predominantemente de su exilio mexicano a Alemania oriental]. Veáse también Reichardt (1987 [1977]) y Dill (2009). Si bien la mayoría de los exiliados se estableció en Alemania oriental, algunos, como Albert Theile, lo hicieron en Alemania occidental. Por otra parte, no era raro que las publicaciones que aparecían en el este circularan, ya sea por transferencia de derechos de publicación o, directamente, por medio de la venta de ejemplares, en el oeste.

3 Para una conceptualización del término y un estudio de casos que incluye el de Gabriel García Márquez, véase Marling (2016). 
jurisdicción. Habría, si la hipótesis es correcta, una literatura capitalista mundial así como una literatura comunista mundial, pero también habría, por ejemplo, una literatura feminista mundial con Jane Austen, Emily Dickinson o Sor Juana Inés de la Cruz en el centro del sistema y con Gustave Flaubert y su madame Bovary en un lugar destacado. Cada una de estas selecciones, a su vez, entraría en conflicto o competencia con los diseños elaborados en otros dominios. La literatura mundial que se convierte en hegemónica, la que se impone y sirve de referencia general, sería, finalmente, la que logra silenciar los diseños rivales. Para el caso de la Alemania dividida, lo que habría sucedido es que, con la Caída del Muro y la posterior disolución de la República Democrática Alemana (RDA), el diseño occidental -la selección de literatura, podríamos decir, que hoy vale como "no marcada" - se habría impuesto y, con ello, sometido a un borramiento total de las memorias archivadas en el país desaparecido.

Creo, no obstante y precisamente por sus complejidades, que el fenómeno de la circulación de literatura en el escenario desdoblado de la Guerra Fría resulta particularmente interesante y que exige un esfuerzo crítico mayor que el habitual. A mi entender, dado que el lugar de enunciación occidental logró imponerse como hegemónico, ahora resulta difícil evaluar, con la objetividad que supone el trabajo de investigación, las dinámicas de la RDA, de la Unión Soviética así como las de la República Popular China anteriores a las reformas de apertura impulsadas por Deng Xiaoping. En el bloque comunista, sin embargo, también habría tomado forma un diseño de literatura mundial donde figuras hoy fundamentalmente ignoradas en Occidente, como Agustín Cuzzani (1924-1987) ${ }^{4}$, habrían ocupado un lugar destacado, y otras, como Pablo Neruda, habrían recibido un impulso decisivo para su consagración también en Occidente. Sucede, y este sería un punto clave, que los prejuicios y estereotipos todavía estarían impidiendo una comprensión refinada de lo que ocurrió al otro lado del Muro en aquel contexto hoy en apariencia tan distante.

\section{II}

La llamativa y con frecuencia ignorada propagación internacional de Jorge Amado $^{5}$, que -como voy a argumentar- va a tener su centro de irradiación en

4 Cuzzani fue un dramaturgo argentino vinculado al grupo de Boedo. Para información acerca de la recepción de Cuzzani en la RDA, véase Kirsten (2004: 178-182).

5 En la reciente biografía de Jorge Amado escrita por Joselia Aguiar se consignan traducciones de sus novelas a cuarenta y nueve lenguas (2018: 292). Marcel Vejmelka, por su parte, destaca la 
la RDA y China, pasa por una instancia previa localizada en los círculos comunistas de Francia. En 1947, el Partido Comunista Brasileño es declarado ilegal y sus miembros se convierten en perseguidos. Amado, que hasta ese momento cumplía funciones de diputado por el estado de São Paulo, se exilió en Francia a comienzos de 1948, donde va a permanecer hasta 1950. Ese año, el Estado francés le retira el permiso de residencia y se ve obligado a trasladarse por dos años a territorio comunista, a Checoslovaquia, desde donde va a realizar frecuentes viajes a los países en la órbita de Moscú, incluida China en 1952 y, más tarde, ya en otro contexto, en 1957. Al momento de su llegada a París, ya existían traducciones de Amado al francés: Bahia de tous les saints (Jubiabá, 1935) y Terre violente (Terras do sem fim, 1943), publicadas, por iniciativa de Henri Malraux, por Gallimard en 1938 y 1946, respectivamente. Pero su inserción en las redes comunistas parisinas, va a catapultar su divulgación en revistas y la traducción de sus novelas al francés. De acuerdo con Marcelo Ridenti,

Jorge Amado foi o artista brasileiro preferido e mais destacado pelas publicações comunistas, especialmente em 1948 e 1949, anos em que esteve exilado em Paris e integrou-se ao meio comunista francês e também internacional, que tinha nessa cidade um dos principais pontos de confluência de suas redes intelectuais (2011: 168).

Durante esos años y los inmediatamente posteriores, la traducción y publicación de sus novelas al francés se aceleró significativamente: Mar morto y $O$ cavaleiro da esperança (Le chevalier de l'espérance) aparecen en 1949; Seara vermelha (Les chemins de la faim) y São Jorge dos Ilhéus (La terre aux fruits d'or), en 1951; Capitães de areia (Capitaines sur sable), en 1952 y Cacau (Cacao), en 1955. Por lo general, estos libros, que se inscriben dentro del paradigma del realismo socialista y de denuncia, fueron publicados por editoriales vinculadas al Partido Comunista Francés, pero también por Gallimard. Este corpus de traducciones al francés - hoy en gran medida olvidado- resulta particularmente significativo si se considera que, por aquel momento, también aparecería Labyrinthes (1953), la primera traducción orgánica de Jorge Luis Borges al francés. Con esta mención, lo que quiero destacar es que, con trece años menos que Borges, Amado, para 1955, superaba vastamente la presencia del primero en el meridiano

singularidad de su caso por la importante y temprana acogida internacional que recibió como escritor de un país que hasta el momento había pasado por completo desapercibido en los debates literarios internacionales: “A importância internacional de Amado é um caso extraordinário, dado que se trata de um escritor brasileiro e de língua portuguesa: O Brasil na época (nos anos 1930/40) praticamente não existia no mapa da literatura mundial, e desde Machado de Assis até hoje constata-se que autores de língua portuguesa, pelo fato de escreverem nesta língua, raramente recebem a projeção internacional merecida” (2014) Ver también Silva 2018. 
de la república mundial de las letras. Y esto no solo en lo que refiere a la arrolladora diferencia en términos de cantidad de traducciones, es decir, en la cobertura de mercado, sino también en lo que respecta a la acumulación de capital simbólico: con publicaciones en Gallimard reseñadas elogiosamente por Albert Camus (veáse Vejmelka 2014, nota 3) y un estrecho vínculo con figuras como Pablo Picasso, Louis Aragón o Jean Paul Sartre, para comienzos de los años 50 Amado ya había encontrado un lugar aventajado, además de en el mercado, en el campo intelectual metropolitano. Lo que sucede, entonces, es que, al margen de la cantidad de publicaciones en la metrópoli, durante estos años afianza su vínculo con el círculo más estrecho de la intelectualidad comunista y simpatizante internacional.

Con su traslado a Checoslovaquia, el reconocimiento con el Premio Lenin originalmente, Stalin - de la Paz en 1951 y sus viajes a la Unión Soviética y a la República Popular China a comienzos de los 50, siempre acompañado de cerca por los futuros premios Lenin de la Paz y Nobel Pablo Neruda y Miguel Ángel Asturias, se acelera su propagación por el mundo comunista que lo terminaría adoptando como uno de sus escritores de referencia y convirtiéndolo en un éxito de ventas.

En la RDA, fundamentalmente dos editoriales van a asumir la difusión de literatura latinoamericana, con mucho más impulso y mucho antes que las editoriales occidentales como Rowohlt, Piper y más tarde Suhrkamp o Wagenbach: Aufbau-Verlag fundada en 1945 y, de manera muy especial, Volk und Welt creada en $1947^{6}$. Ahora el punto no interesa mayormente, pero conviene dejar anotado que las dos han sido vaciadas en manos de las grandes corporaciones del capitalismo neoliberal ${ }^{7}$, lo cual, junto con la desaparición de la RDA y la política de estigmatización de todo lo que fueron sus emprendimientos culturales, puede explicar el borramiento de sus memorias. Los archivos, sin embargo, están a disposición y ofrecen elementos para narrar una historia más próxima al pasado objetivo. Volk und Welt, según estas evidencias, fue un gran importador de literaturas del mundo y un importante espacio de irradiación hacia el

\footnotetext{
$6 \mathrm{Al}$ respecto del programa de estas editoriales, Dieter Reichardt escribe que "las editoriales estatales 'Volk und Welt' y 'Aufbau' de Berlín Oriental se dedicaron sistemática y certeramente a la literatura latinoamericana. Entre 1950 y 1960, editaron, por ejemplo, 8 novelas de Jorge Amado y 9 libros de poemas de Pablo Neruda. A veces hasta consiguieron presentar a un autor latinoamericano antes de que lo hicieron en Francia, como en el caso de Nicolás Guillén de cuya obra $E l$ son entero se publicó la versión alemana en 1952, 3 años antes de salir la versión francesa. Como especialmente meritoria hay que destacar la labor del traductor de Guillén y Neruda, Erich Arendt quien, durante el tiempo del nacionalismo, se exilió en Colombia” (1987 [1977]: 431).

7 Para mayor información al respecto, ver Links (2016 [2010]).
} 
resto del territorio de habla alemana ${ }^{8}$. Walter Czollek, el abuelo del poeta Max, fue su gran animador desde 1950, el año en el que asume la dirección y en el que la editorial publica Jubiabá, la primera traducción de Amado al alemán, hasta el día de su muerte en 1972. La literatura latinoamericana, desde la fundación de la editorial en 1947 hasta su desaparición en 2001, estuvo fuertemente representada en su catálogo, y Jorge Amado fue una figura capital que, al juzgar por los informes de lectura y los tirajes, aunque no siempre respondía a estándares estéticos considerados aceptables por los evaluadores, tuvo una acogida sorprendente por parte del público. Ya en 1962, mucho antes de que en Occidente se desatara la fiebre del boom, solo en la RDA había vendido 300.000 ejemplares de ocho títulos y era un escritor sumamente respetado por la editorial la que, vale aclarar, solo tenía permiso para publicar cinco títulos latinoamericanos por año y, sin embargo, nunca renunciaba a los de Jorge Amado. Con motivo del quincuagésimo cumpleaños de Amado, con fecha del 9 de agosto de 1962, Czollek le envía un telegrama a Río de Janeiro para saludarlo en nombre de todos los empleados de la editorial y recordarle el importante número de 300.000 ejemplares. A continuación, además, agrega:

Con esto usted puede hacerse una idea del enorme eco que su obra ha tenido entre la población de nuestra república. No es poco lo que sus libros han contribuido a promover la amistad de los pueblos entre sus lectores, y, con ello, es usted mismo quien ha apoyado las grandes metas humanistas de nuestro Estado. Por esto, le queremos agradecer el día de hoy (Archivo Volk und Welt, ver anexo 1; la traducción es mía).

También, como muestra el anexo 2, le envía un resumen detallado de los tirajes de todas las ediciones aparecidas entre 1950 y 1962.

Como ya había sucedido con el círculo de intelectuales comunistas en Francia, también en la RDA Amado va a ser un escritor muy respetado en el campo especializado. En 1949, antes de que apareciera la primera traducción de Amado en la RDA, Anna Seghers va a escribir una reseña elogiosa de la traducción al francés de Terras do sem fim, donde va a introducir al escritor brasilero, a quien había conocido personalmente en 1948 (véase Eggensperger 2009), al público de la RDA como un activista político y un narrador realista con una profunda sensibilidad para dar cuenta de las luchas de los sectores populares y

\footnotetext{
8 Para un retrato de la editorial, véase Barck/Lokatis (2005). También puede consultarse el estudio cuantitativo de Siebenmann (1972: 45-47) y Fernández Polcuch (2013). Sobre su experiencia como figura destacada del catálogo de Volk und Welt, Amado escribió: “. . . da Volk und Welt só posso falar bem. Detentora dos direitos de tradução de meus livros na RDA, ela os publicou, a todos eles, boas traduções, belas edições, gráfica primorosa, tiragens enormes, pagou-me os direitos autorais, tudo nos conformes” (1992: 274).
} 
oprimidos (véase Vejmelka 2014). Desde ahí en más, el vínculo entre Seghers y Amado va a ser constante y estrecho, Seghers va a dedicar ensayos a Amado donde lo vincularía con el realismo ruso (véase Eggensperger 2009), y sus biografías van a confluir en diferentes momentos, como cuando en 1951 los dos van a recibir el Premio Lenin de la Paz y, en años posteriores, compartir el jurado del mismo premio con otros escritores del círculo como Ilyá Ehrenburg (véase Alburquerque 2011: 45). Los dos fueron miembros activos del Consejo Mundial de la $\mathrm{Paz}^{9}$ y a comienzos de los años 60 Seghers visitaría dos veces Brasil a instancias de Amado. Hacia mediados de los años 50 la influencia de Amado en el mundo comunista era de tal magnitud, que llegó a interceder en el jurado del Premio Lenin de la Paz para que en 1954 lo recibiera Bertolt Brecht y, así, el escritor alemán eludiera las sospechas del Partido que lo veía como un peligroso formalista (Ridenti 2011: 181; Amado 1992: 193ss.).

Sería posible presentar más datos, como el que refiere al rol de Jorge Amado en el Consejo Mundial por la Paz, pero con los expuestos alcanza para dar cuenta de la importancia de Amado en la RDA. Destaco algunos aspectos antes de trasladar la atención a China: 1. Que la importante recepción de Amado en la RDA se desarrolla muy tempranamente, durante la inmediata Posguerra, antes de que comenzara a tomar forma el así llamado boom y diez años antes de que apareciera, por ejemplo, su primera publicación en España (Lo viejos marineros, Caralt 1961); 2. Que la editorial Volk und Welt, con Walter Czollek a la cabeza y por iniciativa de Anna Seghers, es el gran agente promotor; 3. Que de la RDA, los libros de Amado, ya sea por venta de derechos o la exportación de ejemplares, “viajan” a la República Federal Alemana, a Austria y a Suiza; no al revés, incluso cuando, hacia fines de los años 50, Amado ya se había distanciado de la ortodoxia del estalinismo. 4. Por último, con base en estas evidencias, que se puede sostener que hay un borramiento de esta memoria (que, por supuesto, incluye también a Asturias o a Neruda). Marcel Vejmelka anota que “Até a década de 1990, Jorge Amado era o escritor brasileiro mais conhecido e influente na Alemanha. Hoje, a sua posição mudou consideravelmente" (2014: s.p.). Creo, no obstante, que existen elementos como para decir más; a partir de los testimonios conservados en notas de prensa y en archivos, se podría sostener que, promovido desde la RDA, Jorge Amado fue hasta la aparición de Isabel Allende a mediados de los 80, el escritor latinoamericano con mayor reconocimiento en el territorio de habla alemana en general.

9 Un estudio muy bien documentado sobre este organismo, que también ilumina el tejido de redes intelectuales en el contexto de la Guerra Fría, se puede encontrar en Iber (2015, capítulo II). 
Pasemos a la República Popular China. El 31 de enero de 1952, después de haber conocido a Emi Siao en Checoslovaquia (Wang 2019: 75), Jorge Amado llega por primera vez a Peking acompañado por Nicolás Guillén: "Waiting for them at the airport were some of China's most influential writers, including Guo Moruo, Mao Dun, Ai Qing, and Emi Siao” (Wang 2019: 74). Cinco años después va a volver en compañía de Pablo Neruda. Desde 1951, cuando recibe el Premio Lenin de la Paz, comienzan a aparecer notas elogiosas en diferentes medios de prensa chinos, entre ellas, un ensayo de Emi Siao dedicado a Amado y a Guillén, donde Siao informa sobre las actividades políticas de Amado en Brasil y lo exalta como un resuelto revolucionario (véase Wang 2019: 79 nota 36) ${ }^{10}$. Según informa Siwei Wang, la primera traducción al chino, de Terras do sem fim (1943), la hace Wu Lao desde el inglés en 1951, antes de que Amado hiciera su primer viaje a China. A partir de ese momento, comienzan a sucederse las traducciones, desde el francés, el inglés o el ruso, de manera que para su segundo viaje los lectores chinos ya tenían a disposición cinco novelas y se podría decir que estaban familiarizados con el escritor. Escribe Siwei Wang, en la misma línea que Marcel Vejmelka para el caso de la RDA, que ya en aquel entonces "No other Brazilian writers enjoyed the same level of reverence accorded to Jorge Amado” (2019: 80). Los tirajes, al igual que en la RDA, no son menores, de las primeras novelas, las reediciones se suceden, solo en los años 50 Terras do sem fim se reeditó tres veces con 34.500 copias, São Jorge dos Ilhéus dos con 16.300 ejemplares, y de Seara vermelha salieron cuatro ediciones y 31.500 copias.

Por otro lado, Amado se convierte también en un gatekeeper de la literatura china en Brasil. Como editor de la publicación Para todos, entre 1956 y 1958, y

10 También Jianbo Zhang comenta las notas elogiosas que desde comienzos de los años 50 se publicaron en China sobre Jorge Amado. Por regla general, estas notas, antes que el aspecto formal de su escritura, destacaban su militancia comunista, su activismo por la paz y su compromiso con las causas de los sectores excluidos. "No contexto dos escritores da América Latina”, escribe Zhang, “os dois que exerceram maior influência sobre os chineses foram o poeta chileno Pablo Neruda (1904-1973) e o romancista brasileiro Jorge Amado (1912-2001), por serem ambos membros do partido comunista. As posturas políticas evidenciadas em suas obras foram certamente os maiores motivos que os levaram à China.

Em 1951, Jorge Amado recebeu o Premio Stalin da Paz entro os Povos, tornando-se uma espécie de embaixador cultural comunista do Brasil. Foi justamente nesse ano que Jorge Amado foi apresentado, na China, pela revista Combecimentos Mundiais, em artigo intitulado 'O Lutador da Paz no Brasil: o Poeta Jorge Amado'” (Zhang 2013: 28). La revista, fundada en 1934, era una herramienta del Partido Comunista, y el autor de la nota, Huai Liu: "O perfil de Jorge Amado, como escritor comunista, foi nitidamente traçado nesta breve apresentação: os chineses o viam, nessa época, essencialmente como uma figura política. Sua obra era avaliada, nesse contexto, sobretudo por seu posicionamento ideológico, e não por seus valores estético-literários” (Zhang 2013: 29-30). 
director de la colección "Romances do povo" de la editorial Vitória no va a ahorrar esfuerzos para dar a conocer en Brasil la literatura china. Una tarea que ya había comenzado en 1945 como traductor desde el francés y que al día de hoy se podría decir que fue el emprendimiento orgánico más consecuente para divulgar literatura china en Brasil.

De acuerdo con Zhang (2013), la divulgación y recepción de Amado en China pueden dividirse en dos grandes momentos. Durante los años 50, cuando se traduce su producción temprana, y realista, a través de otras traducciones y donde su militancia comunista es el gran motivo que las impulsa, y, luego, a partir de 1981 cuando la prestigiosa revista Shijie wenxue - Literatura mundial- retoma la agenda y publica A morte e a morte de Quincas Berro D’água (1959) traducida directamente desde el portugués. Con la traducción de esta novela, que por aquel entonces era el sexto libro de Amado disponible en China, se inaugura otro intenso periodo de traducciones que excede el marco temprano del realismo y el compromiso, y que va a comenzar a retrotraerse en los últimos años. Aun con el decaimiento actual y sin que se hayan traducido sus obras completas, Zhang argumenta que

A tradução das obras de Jorge Amado na China não aconteceu por acaso e tem condições ideológicas e históricas. Nos seus dois momentos importantes na China, 15 obras completas foram traduzidas de diversas línguas (russo, francês, espanhol, e português) para o chinês. Com esta quantidade de obras conhecidas pelos leitores chineses, Jorge Amado e, sem nenhuma sobra de dúvida, o escritor brasileiro mais importante da difusão da literatura brasileira na China (2013: 44).

Y lo mismo que en la Francia de fines de los 40 o en la RDA a comienzos de los 50, esta afirmación no posee validez solo en términos de mercado, sino también por la consideración del campo intelectual representado por los escritores chinos más prestigiosos, como Emi Siao, y las publicaciones de referencia. Hacia los años 90, comenta Siwei Wang en cierta consonancia con Zhang, se produce un cambio en el interés por Amado, ya no va a estar centrado en sus retratos de la explotación y el paisaje local y dominado por una representación del nordeste brasilero como territorio destinado a la revolución, sino por el componente erótico de sus textos. Lo cierto es que todavía en los años 90 Amado seguía siendo un escritor sumamente leído así como descuidado por la crítica académica occidental. Argumenta Wang que esto se debe a que la crítica latinoamericanista concentra su atención en la literatura redactada en castellano y tiende a relegar o ignorar la lusófona. Otro argumento sería que a esa misma crítica le resulta difícil tomar distancia del relato del boom y depositar la atención en coyunturas y espacios alternativos a los que ha encumbrado el capitalismo occidental. En cualquier caso, sostiene Wang, la operación centrada en el boom y en el castellano "fails to explain 
why the canonization of Brazilian literature surprisingly maintains its stability by according Jorge Amado the most important status for more than fifty years" (2019: 72). Por mi parte, agregaría que la crítica y la investigación, además de que probablemente sí privilegian el castellano frente al portugués, el francés y las lenguas vernáculas de América Latina, tienden a centrar la atención no solo en el mundo occidental sino también en los mercados europeos y estadounidense y, con eso, fallan a la hora de dar cuenta de flujos alternativos - el que va del nordeste brasilero a Peking, por ejemplo- a los que siguen el patrón clásico de circulación colonial.

\section{III}

A partir de la sucinta revisión de este caso, algunas ideas que se podrían extraer como conclusión serían las que siguen. Primero, y ante todo, que la consulta de archivos es una herramienta útil que permite revisar las memorias oficiales y elaborar historias alternativas. De ninguna manera se trata de elaborar una hagiografía de Jorge Amado o exaltarlo, eso está claro, pero no creo que un relato sobre la propagación mundial de literatura latinoamericana centrado en Vargas Llosa y García Márquez sea del todo veraz; por lo menos no uno imparcial. Al menos habría que admitir que, antes de su irrupción en el escenario internacional, la literatura latinoamericana ya era conocida tanto en Alemania como en China y, posiblemente, en muchos otros dominios geopolíticos, como la Unión Soviética donde La vorágine (1924), Doña Bárbara (1929) y El señor presidente (1946) fueron títulos con una enorme aceptación por parte del público y de la crítica (véase Rupprecht 2015: 107) ${ }^{11}$. Solo que esa literatura conocida con anterioridad era diferente, tenía otros protagonistas. Tampoco era literatura que, como sucede desde el boom en adelante, estaba obligada a pasar por el sistema de agentes y de la industria editorial concentrada en Barcelona o por la Feria del Libro de Frankfurt para, en un segundo momento, alcanzar un público fuera del circuito hispanohablante. Los exiliados alemanes que regresaron a Alemania en la Posguerra o los viajeros a la República Popular China de los años $50^{12}$

\footnotetext{
11 Para el caso de Amado en la Unión Soviética, donde aparece traducido por primera vez en 1948, véase Rougle (1984) cuyas líneas introductorias afirman que "No Latin American writer has received as much attention in the Soviet Union as has the Brazilian novelist Jorge Amado" (35). 12 Para mayor información al respecto, ver el dossier "El viaje América Latina-China. Una interacción sur-sur sui generis" en la revista TRANSMODERNITY: Journal of Peripheral Cultural Production of the Luso-Hispanic World: https://escholarship.org/uc/ssha_transmodernity/9/3.
} 
fueron agentes de primera mano que aportaban materiales directamente de las fuentes ${ }^{13}$. Los mediadores así constituidos seleccionaban y jerarquizaban, sí, pero esa tarea estaba en manos de escritores y traductores más o menos vinculados biográficamente a América Latina, no de mediadores de la industria editorial metropolitana. Para el caso de Amado, las redes intelectuales amalgamadas por una mayor o menor filiación comunista, primero en Francia y después en la RDA y China, le garantizaron el aval de verdaderos gatekeepers, como Albert Camus, Anna Seghers y Emi Siao, quienes impulsaron su incorporación a catálogos como el de la editorial Volk und Welt y una inserción privilegiada en los mercados respectivos ${ }^{14}$.

Otro punto destacable sería que la literatura mundial es algo contingente, variable en el tiempo y en el espacio. Privilegiar un recorte frente a otros es siempre una operación ideológica, de compromiso consciente o inconsciente con un proyecto político. Cada realidad o cada submundo busca establecer su recorte, pero, finalmente, uno se impone como hegemónico y se filtra en los dominios rivales. ¿Cuántos son los Premios Nobel de Literatura suecos? ¿Siete? Esa sería una prueba contundente. La literatura mundial es, por consiguiente, siempre una percepción ideológica de las literaturas del mundo centrada en el sujeto, ya sea individual o colectivo, de enunciación. Cuanto mejor es la posición de ese sujeto de enunciación en la estructura general, tanto mayor es la posibilidad de que imponga su percepción al resto de los sujetos.

13 Sobre estos últimos, Guangfu Chen anota que "La proclamación de la nueva China en 1949 abrió un ancho camino para el intercambio entre los escritores chinos y sus colegas extranjeros. En 1951 [sic; Amado, en realidad, en 1952], Pablo Neruda y Jorge Amado viajaron por China, iniciando así el contacto directo entre los escritores chinos y los latinoamericanos. Ambos dieron a conocer a los chinos lo que es la literatura latinoamericana. Siguieron sus pasos Nicolás Guillén y Miguel Ángel Asturias” (1984: 278).

14 La difusión temprana y orgánica de Amado en los circuitos comunistas internacionales contrasta con la propagación tardía o fragmentaria que obtuvo en los dominios capitalistas más bien recién después de que abandonara su compromiso explícito con el Partido Comunista y el paradigma realista. En lo que respecta a la Alemania dividida, Vejmelka anota que "Na Alemanha Ocidental ocorre, em comparação com os campos aqui contemplados [el circuito comunista], uma descoberta atrasada de Jorge Amado. Nos anos 1950 não é completamente desconhecido na RFA, existem traduções, mas são poucas e circulam à margem do campo literário, em pequenas editoras e na Áustria, incluindo traduções licenciadas da RDA. Amado ganha presença concreta só em 1963, não por acaso com Gabriela, cravo e canela. A tradução publicada na RDA em 1962 é relançada pela editora Rowohlt na RFA e, ironicamente, continua sendo a única alemã até hoje: uma tradução socialista do primeiro best seller na Alemanha capitalista” (2014). En EE.UU. y el mundo anglófono se registra una traducción pionera de Terra do sem fim en 1945 y, después, un gran vacío hasta la traducción en 1962 de Gabriela, cravo e canela (1958) (véase Melo 2017: 12). 
La "literatura comunista mundial" sería, desde este punto de vista, una percepción derrotada por su percepción rival más prominente, la del capitalismo. No creo que haya sido derrotado un lenguaje literario, el del realismo socialista. No creo que la literatura comunista mundial sea equiparable al realismo socialista ${ }^{15}$. Jorge Amado lo incursionó solo en algunos trazos de su escritura. Y la consulta de archivos permite ver que muchos textos fueron aprobados para la publicación en la RDA aunque no se ajustaban a lo que se consideraba realismo socialista, fuere lo que fuere. Tampoco sería difícil encontrar novelas realsocialistas dentro del imperio del capitalismo global, enfocadas, por ejemplo, en la vida en las favelas de Brasil o las comunas de Medellín. La literatura comunista mundial se apoyaba, ante todo, en una red de cierta empatía ideológica y en un mercado concomitante: Ilyá Ehrenburg, Ai Qing, Jean Paul Sartre, Jorge Amado y María Rosa Oliver compartieron esa red que, por un momento - creyeron, y después se desengañaron- ya era un mundo alternativo.

15 K. Geißler introdujo en 1984 el concepto de 'literatura socialista mundial' para referirse al corpus internacional susceptible de ser alineado bajo el paradigma del realismo socialista, es decir, uno que no solo ni necesariamente se fue gestando en los países que adoptaron el comunismo. "Sozialistische Weltliteratur ist nicht identisch mit der Literatur der sozialistischen Welt. Sie ist die Literatur der sozialistischen Gedanken- und Ideenwelt. Auch für sie gelten die Beziehungen von Produktion, Vermittlung und Rezeption. Wenn wir sozialistische Weltliteratur als ein System aufeinander einwirkender sozialistischer Literaturen verstehen wollen, so entwickelt sie sich als Folge der mit dem Weltkrieg und der Großen Sozialistischen Oktoberrevolution gegebenen internationalen Bedingungen. Die Literatur des sozialistischen Realismus, in erster Linie die Sowjetliteratur, ist ihr Zentrum, denn sie ist am engsten mit dem Kampf der Arbeiterklasse um die Eroberung der politischen Macht und um die Umgestaltung der Welt verbunden” (1984: 668) [La literatura socialista mundial no es idéntica a la literatura del mundo socialista. Es la literatura del mundo de los pensamientos e ideas socialistas. Las relaciones de producción, mediación y recepción también valen para ella. Si queremos entender la literatura socialista mundial como un sistema de literaturas socialistas en interacción, ella se desarrolla como resultado de las condiciones internacionales dadas con la Guerra Mundial y la Gran Revolución Socialista de Octubre. La literatura del realismo socialista, sobre todo la literatura soviética, es su centro porque está más estrechamente relacionada con la lucha de la clase obrera por la conquista del poder político y la transformación del mundo]. La "literatura comunista mundial", según los argumentos que he expuesto, no coincidiría con la definición de Geißler pues estaría conformada por la literatura internacional en circulación en el mundo comunista, independientemente de que su línea estética pueda ser clasificable como real-socialista o no. Después del segundo viaje a China en 1957, Amado abandona la ortodoxia realista y de denuncia con lo cual, no obstante, no sacrifica su protagonismo en el mundo comunista. 


\section{Bibliografía}

Aguiar, Joselia (2018): Jorge Amado: uma biografia. São Paulo: todavia.

Amado, Jorge (1992): Navegação de cabotagem. Apontamentos para um livro de memórias que jamais escreverei. Río de Janeiro: Record.

Alburquerque F., Germán (2011): La trinchera letrada. Intelectuales latinoamericanos y Guerra Fría. Santiago de Chile: Ariadna Ediciones.

Barck, Simone/Lokatis, Siegrfried (eds.) (2005 [2003]): Fenster zur Welt. Eine Geschichte des DDR-Verlages Volk \& Welt. Berlín: Ch.Links.

Becerra, Eduardo (2008): “Proceso de la novela hispanoamericana contemporánea. Del llamado regionalismo a la supuesta nueva novela: 1910-1975”. En: Barrera López, Trinidad (ed.):

Historia de la literatura hispanoamericana, Vol. 3. Madrid: Cátedra, pp. 15-32.

Chen, Guangfu (1984): “La literatura latinoamericana en China”. En: Estudios de Asia y África, 19, 2 (60), pp. 278-285.

Dill, Hans-Otto (2009): Die lateinamerikanische Literatur in Deutschland. Bausteine zur Geschichte ihrer Rezeption. Fráncfort del Meno: Peter Lang.

Donoso, José (1972): Historia personal del “boom”. Barcelona: Anagrama.

Eggensperger, Klaus (2009): "Ideias napoleônicas e o grande inquisidor: sobre a militância comunista de Anna Seghers e Jorge Amado". En: Revista Contingentia. Journal des deutschen Sektors der UFRGS 4/2, pp. 1-10, <https://seer.ufrgs.br/contingentia/article/ view/8714> (última visita: 11/11/2019).

Fernández Polcuch, Martina (2013): "Versiones germano-orientales de la literatura argentina”. En: Exlibris 2, pp. 96-111, <http://revistas.filo.uba.ar/index.php/exlibris/article/view/ 373/242> (última visita: 11/11/2019).

Fuentes, Carlos (1969): La nueva novela hispanoamericana. México: Joaquín Mortiz.

Geißler, K. (1984): “Probleme sozialistischer Weltliteratur”. Zeitschrift für Slawistik 29/5, pp. 665-673.

Iber, Patrick (2015): Neither Peace nor Freedom. The Cultural Cold War in Latin America. Cambridge/Londres: Harvard University Press.

Kirsten, Jens (2004): Lateinamerikanische Literatur in der DDR. Publikations- und Wirkungsgechichte. Berlín: Ch.Links.

Links, Christoph (2016 [2010]): Das Schicksal der DDR-Verlage. Die Privatisierung und ihre Konsequenzen. Berlín: edition berolina.

Locane, Jorge J. (2019): “Albert Theile, mediador pioneiro. Los exiliados alemanes en América Latina y la publicación de literatura latinoamericana en el mundo germanohablante en el período de Posguerra". En: Revista Chilena de Literatura, 100, pp. 379-389.

Marling, William (2016): Gatekeepers. The Emergence of World Literature \& the 1960s. Nueva York: Oxford University Press.

Reichardt, Dieter (1987 [1977]): “Inventario de la recepción de la literatura latinoamericana en los países de habla alemana”. En: Rall, Dietrich (comp.): En busca del texto. Teoría de la recepción literaria. México: Universidad Nacional Autónoma de México, pp. 423-433.

Ridenti, Marcelo (2011): “Jorge Amado e seus camaradas no círculo comunista internacional”. En: Sociologia \& Antropologia 1/2, pp. 165-194.

Rodríguez Monegal, Emir (1970): “La nueva novela latinoamericana”. En: Actas del III Congreso de la Asociación Internacional de Hispanistas: celebrado en México D.F. del 26-31 de agosto 1968. México: El Colegio de México, pp. 47-63. 
Rougle, William (1984): “Soviet Critical Responses to Jorge Amado”. En: Luso-Brazilian Review $\mathrm{XXI} / 2$, pp. 35-56.

Rupprecht, Tobias (2015): Soviet Internationalism after Stalin: Interaction and Exchange between the USSR and Latin America during the Cold War. Cambridge: Cambridge University Press.

Siebenmann, Gustav (1972): Die neuere Literatur Lateinamerikas und ihre Rezeption im deutschen Sprachraum. Berlín: Colloquium.

Silva, Márca Rios da (2018): “Jorge Amado: The International Projection of the Brazilian Writer”. En: Coutinho, Eduardo F. (ed.): Brazilian Literature as World Literature. Londres/ Nueva York: Bloomsbury, pp. 199-220.

Melo, Cimara Valim de (2017): "Mapping Brazilian Literature Translated into English". En: Modern Languages Open, <http://doi.org/10.3828/mlo.v0i0.124> (última visita: 11/11/2019).

Vargas Llosa, Mario (1969): “Novela primitiva y novela de creación en América Latina”. En: Revista de la Universidad de México 10, pp. 29-36.

Vejmelka, Marcel (2014): “Entre o exótico e o político: caraterísticas da recepção e tradução de Jorge Amado na Alemanha". En: Amerika. Mémoires, identités, territoires 10, 〈https://journals.openedition.org/amerika/4522〉 (última visita: 11/11/2019).

Wang, Siwei (2019): “Transcontinental Revolutionary Imagination: Literary Translation between China and Brazil (1952-1964)”. En: Cambridge Journal of Postcolonial Literary Inquiry 6/1, pp. 70-98.

Zhang, Jianbo (2013): “A recepção das obras de Jorge Amado na China”. En: Cadernos de Literatura em Tradução 14, pp. 23-48.

\section{Documentos de archivo}

Czollek, Walter (1962): “Telegramm an Jorge Amado”. Archivo Volk und Welt, Akademie der Kunste (Ref. VuW 1401).

Czollek, Walter (1962): “Amado-Titel und Auflagen”. Archivo Volk und Welt, Akademie der Kunste (Ref. VuW 1401). 


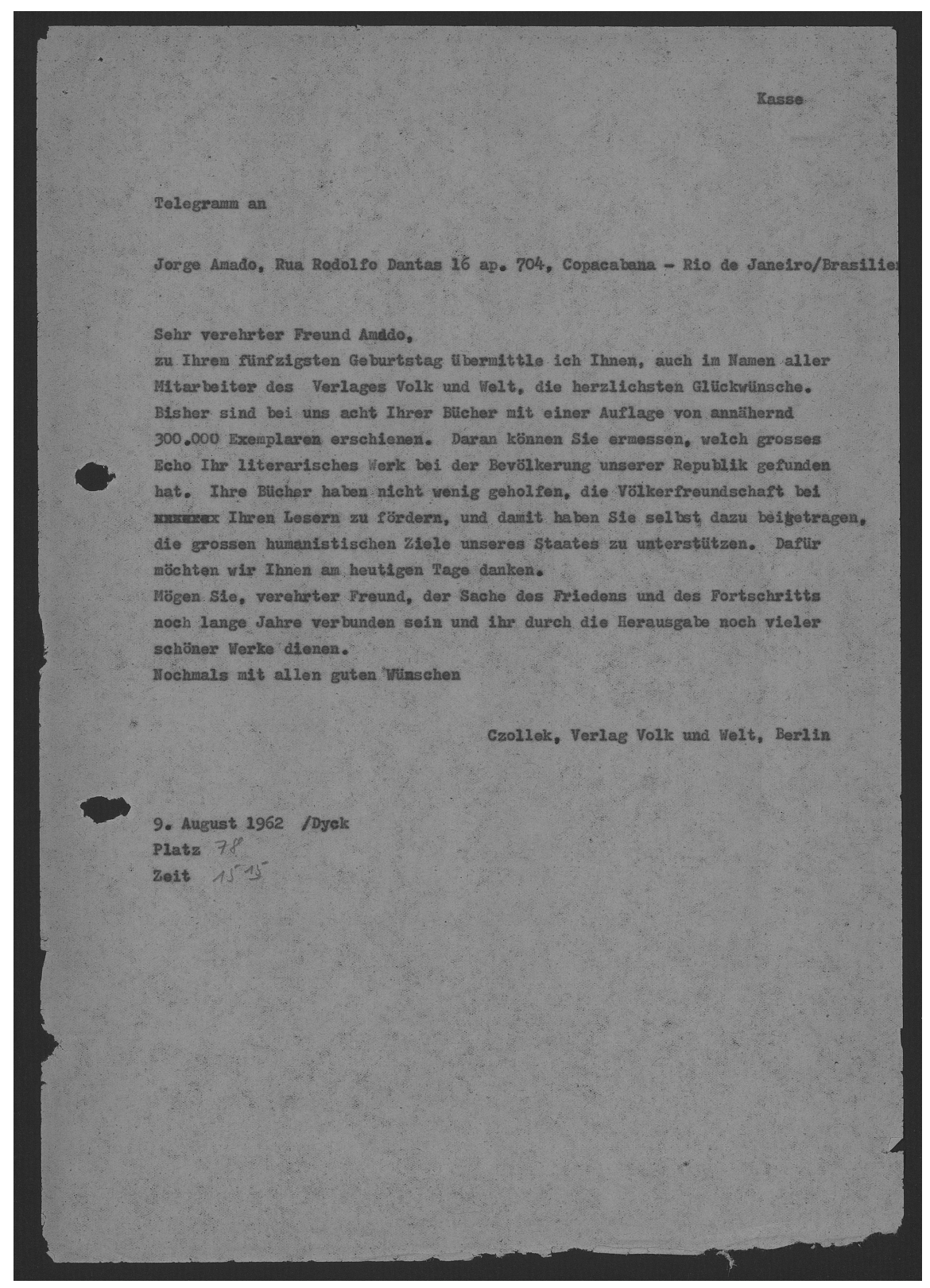

Anexo 1: telegrama de Walter Czollek a Jorge Amado. 


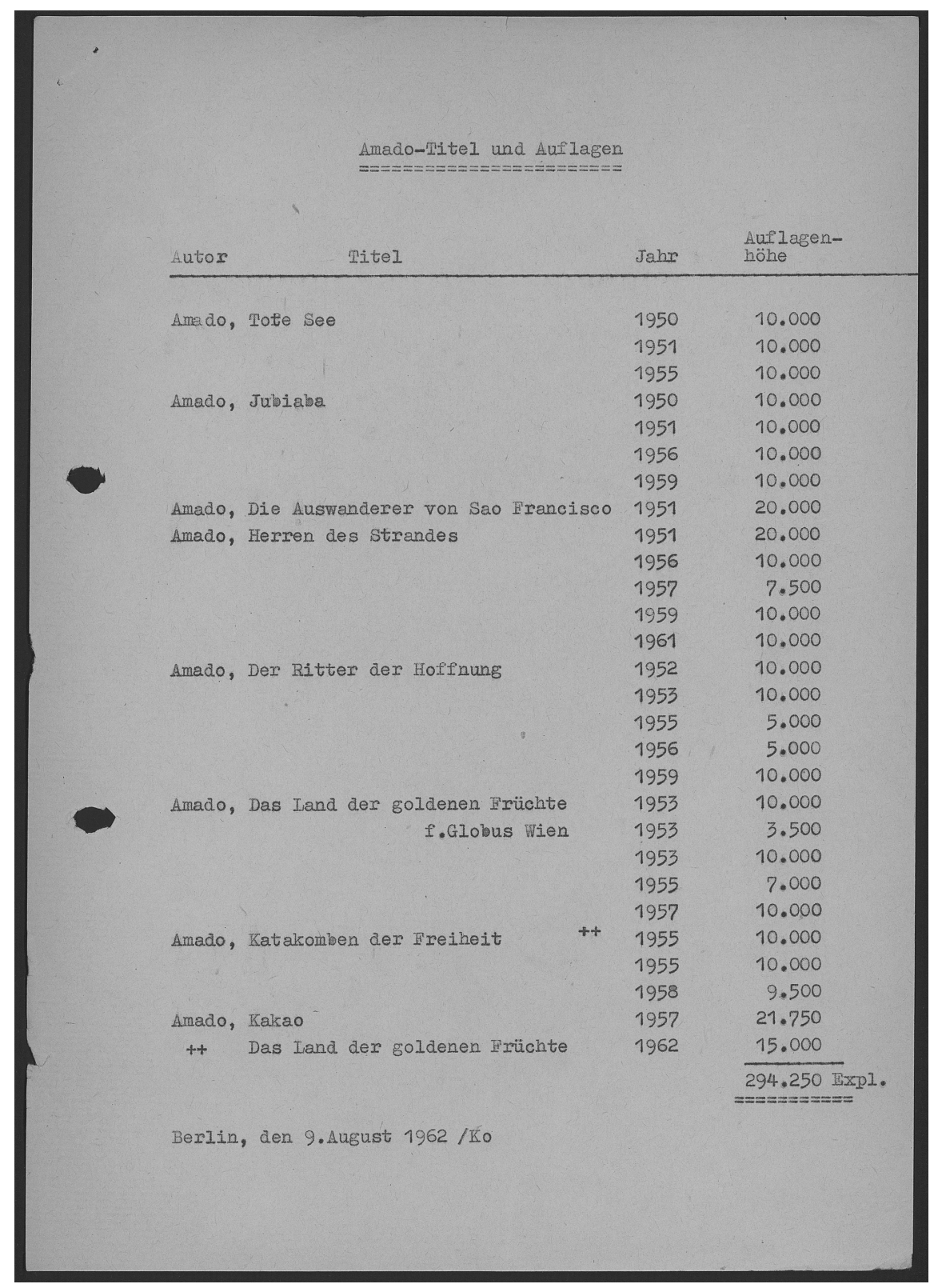

Anexo 2: resumen de ejemplares de Jorge Amado publicados por Volk und Welt entre $1950 \mathrm{y}$ 1962. 
